\title{
LA MAGIA DE LA CREACIÓN ${ }^{1}$
}

The magic of creation

\author{
Matías Vial V. \\ Facultad de Artes \\ Universidad de Chile
}

Afirmar que hay magia en el arte no es un decir, no es una forma de adornar el hecho con una sentencia poética. Lo considero real.

Tal vez, la experiencia de escultor es la que me haya llevado a pensar lo que anteriormente afirmo, ya que no hay nada de ello que no fuera vivenciado personalmente.

Creo que si el arte no es un movimiento apasionado, nada vale. Así, no se es escultor, sólo cuando se establece diálogo con la materia; se es en todo momento. $\mathrm{Y}$ en esta permanente búsqueda de metáforas no podemos confiar más que en la propia sensibilidad, la que nos guía y auxilia. Por esto, no podremos dejar de considerar la inmensa riqueza que guarda la imaginación, la que hace de camino que nos lleva a conocer verdades secretas.

Pero ya es tiempo de establecer aquello de que la creatividad es un don divino que hace las veces de simiente en cualquier realización y con ello quiero decir que no es susceptible de aprendizaje, aunque sí de cultivo, de modo que como cualquier potencia debe desarrollarse.

En el campo del arte he experimentado cuán tiempo perdido es tratar de enseñar o siquiera incentivar, a quien carece del don de la creatividad. Así se puede aprender pintura o escultura, se puede aprender a ser escultor o pintor, pero es imposible aprender a crear.

\footnotetext{
${ }^{1}$ Publicado en VI Jornadas Interdisciplinarias. Páginas 195 - 200.
}

Cuadernos Judaicos ISSN: 0718-8749 
El que no siente la emoción del acto creador sencillamente debe renunciar a él. Pero ¿cuál es el mecanismo que funciona en dicho acto? Desde luego no es un hecho intelectivo. Más bien, es la intuición al servicio de algo emotivo; es una forma de amar a la cual ninguna lógica pudiera dar razones y que, por tanto, está rodeado de un mágico misterio, misterio que sólo el artista es capaz de interpretar, a partir de su experiencia sensorial, la que al pasar a través del tamiz de su sensibilidad se materializa en otra, la que es espejo del autor.

De este modo, enfrentar la realidad objetiva interpretándola a través de un proceso de transformación y reformas con una actitud contemplativa ha de ser lo primero. Y así como al místico el estado de éxtasis le traza un nivel de existencia para ordenar su vida embriagado de amor, el escultor se embriaga de imágenes, cuyo espíritu clama por inaugurar. Esas formas y ese estado determinan también un nivel de existencia que lo conduce a ordenar su vida sometiendo cualquier otra preocupación a su quehacer.

No sólo la vista y el tacto son canales de la percepción; la memoria va almacenando en su misteriosa estructura, recuerdos y sensaciones, de modo que factores impensados como el sabor de una fruta, una melodía escuchada al pasar o el recuerdo del rostro de una mujer, despiertan imágenes dormidas, las que, estimuladas por el reencuentro del recuerdo o de la sensación que las genera, no pocas veces adoptan en el proceso, -al sentirse postergadas, o bien en el olvido, maduras-, la violencia de las crecientes. Otras, una porfiada espera precisan para desarrollarse, en que la reflexión, sedimento fecundo, es indispensable para lograrlo. Pues, del mismo modo como la semilla enterrada, necesita estratificarse, a la voluntad de forma le es indispensable un largo período de reposo durante el cual se va diluyendo todo aquello que no tiene sustancia metafórica, transmutándose en arte lo que, liberado del objeto, entra en la dimensión del espíritu y aunque hunda sus raíces en la realidad objetiva del artista, extrae sólo de ahí el alimento de su hacer.

Podemos afirmar que la creación es la imaginación fecundada que da luz a una verdad nueva que no es otra que la obra de arte. 
El escultor transmuta la materia utilizando elementos arrancados de lo real para recrear el mundo transcendiéndolo.

El artista, cualquiera sea su forma en que se exprese, es hilo conductor que une dos estados: el de la sensación y el de la cristalización de vivencias y es el instrumento que de todo sabe sacar destellos que son lo absoluto de un universo en que todo es relativo. El creador es vencido y desaparece; pero la obra de arte de este permanece cuando realmente lo es.

Santa Teresa de Avila, conocedora profunda del corazón humano dejó escrito: "El hombre necesita de delectaciones y cuando no las encuentra en el espíritu, recurre a las que los sentidos le proporcionan”.

Esto me lleva a considerar ¡cuán curiosa es la actitud del creador! quien, usando de los sentidos para atesorar su acervo de vivencias, las torna en valores espirituales, al transmutarlas. Pero lo que no es exagerado hablar de una transubtanciación de la materia, al referirse al proceso de creación artística.

Este mundo original e intransferible creado por él y del que es responsable, es el que entrega a la sociedad, originándose de este modo el problema de la ética en la creación.

Por otra parte quisiera destacar el mágico papel del azar en el desarrollo del proceso. Desde el inicio del coloquio con la materia, la intuición se torna en mi guía sensual frente a ella, debiendo hacer un esfuerzo por dejar de lado todo proceso diegético, ya que sólo cuentan entonces los valores materiales propios de la piedra o el bronce, en orden a sacar de ellos el mejor partido pues la materia, rica y sugerente en diálogo, se vale del cristal del mármol o de la vibrante resonancia del bronce para hacernos oír su voz a fin de lograr el contacto entre ella y el escultor en el acto de amor en que se lleva a cabo la creación.

No oír la voz de la materia o imponer una voluntad despótica sobre ella, causaría la ruptura de este diálogo y con ello la destrucción de la imagen. Por otra parte, como lo enunciara 
anteriormente, azares como las fallas estructurales de los bloques, muchas veces obliga a efectuar cambios en el plan preconcebido o quizás una trizadura, un nudo o una mancha me fuercen a ello, a abandonar la obra a medio empezar y ¡cuántas veces! estos afortunados fracasos sugieren, pasado el tiempo, soluciones infinitamente más ricas que las propuestas al comienzo.

Otro aspecto mágico en el hecho de la creación plástica lo constituyen los aspectos literales del arte.

Sea el modelo objeto o no, vale decir, a modo de ejemplo desnudo vivencia recordada, se dice en ocasiones el artista: "Está la obra hecha", con lo cual quiere expresar alguna forma de identidad entre la percepción de un fenómeno físico y la función creativa.

Naturalmente esta forma de empatía no identifica lo uno con lo otro. Mas algo inexplicable por la razón hace del ente empatizado algo del cual "soy parte y del que él es parte mía", algo que va más allá de la transcripción poética, de un hecho en el cual no están puestos mis intereses. Así, a modo de ejemplo, diré que me es muy diferente, por tanto, "descubrir" una piedra en la cual esté identificada y contenida mi voluntad de forma, que un modelo con el cual no tengo compromiso afectivo.

No pretendo que los ejemplos del modelo antedicho así como la piedra que sugiere mi escultura "lo sea". No obstante cualquiera que haya experimentado ese estado de comunicación, convendrá en que en este caso se está pisando el umbral del mito, sumergidos en la magia de la creación, ya que lo antes expuesto "ocurre" y no en forma metafórica sino literal.

Y me hago la pregunta: ¿No es este identificarse con el objeto amado una forma de magia, o será sólo alguna fuerza desconocida que el hecho de la creación conlleva en determinados momentos? 
Súmese a esta situación ese coloquio íntimo, secreto, intransferible entre materia y artista en el momento de la creación y ahí creo poder afirmar que el arte es magia, ya que este coloquio amoroso constituye un verdadero orgasmo en que vivencia y materia cristalizan en la obra de arte.

Momento no controlado por la razón es aquel en que el escultor y la piedra, el payador y la guitarra se refieren al objeto de su amor, objeto que deviene en sujeto con voz propia, creándose de este modo una invención a tres voces: artista, materia y objeto amado, lo que da origen a la obra de arte.

¿Quién es en este momento sujeto y quién atributo? Tanta autonomía han adquirido tallador y mármol, tanta que basta que uno violente al otro para que este mágico coloquio se cambie en retorno a las individualidades mudas

Es experiencia de taller aquello de que el escultor debe oír la voz de la piedra que claramente le sugiere cómo tallarla y que debe tener la entereza de no desvirtuar la imagen por las infinitas sugerencias que le brinda, sino dirigirla amorosamente con su cincel con el fin de materializar el objeto amado, el cual, -al concretarse-, deja de serlo para devenir en piedra amada, proyección de mí.

El arte es mi opinión parcial del entorno y, por tanto, una forma de conocimiento opuesta a la del científico que tiende a la imparcialidad. La mía es arbitraria, interesada, ya que no está en mi naturaleza poder actuar de otro modo. Así cuando digo ante una mujer hermosa "ni modelada por mí", en ese ni estoy afirmando la diferencia de identidad entre la bella y lo por mí modelado reconociendo la magia de la metáfora que opera en el arte.

Veamos en qué sentido lo afirmo. En el Libro del Génesis se llama a la Serpiente, Padre de la Mentira. Del mismo modo llama la mitología Maya Kiche a Wacamayor, aunque en sentido bien diferente. 
La serpiente reptante y venenosa encarna al demonio para engañar a la mujer en la metáfora serpiente-demonio, ya que al espíritu del mal, al padre de la mentira venenosa y escurridiza, se le materializa en el reptil que posee iguales atributos.

Wacamayor Rojo es un trapalón, un mentiroso que no encarna a nadie. Ya su presencia multicolor le sirvió para decir al hombre yo soy el sol. Wacamayor Rojo habla con voz humana y es una esencia mentirosa (estamos en presencia de la inmediatez entre el pájaro y su esencia de mentira donde no cabe metáfora).

He tratado de analizar contenidos literales en el arte o si se quiere, inmediatos, teniendo presente que a pesar de su carga mítico mágica es a mi ver gran metáfora. Insisto, lo veo en un como si que explicaría la conducta del actor el que por muy posesionado que esté de su papel, nunca pierde conciencia de su identidad. Nunca Otelo apuñalará realmente a Desdémona, al menos en las tablas, y, por mucho que se emocione al público espectador, jamás perderá conciencia de su condición de tal.

Proceder de otro modo sería locura propia de Don Quijote, sería el actuar de éste ante el retablo de Maese Pedro, donde la confusión entre ficción y realidad le llevó en un acto del valor a destripar los muñecos.

Ahora mi pregunta es: Ya que el mito está plagado de magia y de metáforas ¿son éstas tan poderosas para hacer del primero un "como si"?

Veamos: cuando un sacerdote azteca arrancaba el corazón del sacrificado, estaba dando de beber sangre al sol para que éste pudiera renacer a la siguiente madrugada.

Hay en este sacrificio y el sol naciente una analogía en rojo lo que sin duda conlleva una gran carga mágica metafórica. Mas, para el pueblo Nahuatl, lo que realmente importaba era la firma convicción de que si no se daba de beber sangre al sol, éste no renacería a la siguiente aurora. Y es por eso que morir sacrificado constituía un honor y más que eso una forma de integración.

Cuadernos Judaicos ISSN: 0718-8749

Volumen Aniversario 50 años 
A mi modo de ver, el acto creativo está sumido en una atmósfera mágica y, de no ser así, pobre sería. Así como pienso que arte y mito están contiguos mas no se identifican, arte y magia se topan en el acto de la creación. Así creo que el arte es siempre mágico y la magia puede ser una forma de arte.

Otro aspecto de lo mágico del arte nos lo muestra el hecho de que la realidad y la ficción se entrelazan de tal modo que se produce una situación en la cual no es posible definir los límites entre ambas. Así ante un esclavo de Miguel Angel ¿qué vemos? ¿un esclavo? Claro que no. ¿Vemos un ser humano? No, pues no hay seres humanos de mármol. Entonces ¿qué hay frente a nosotros?

Encontramos un bloque marmoreo con ciertas rememoranzas del cuerpo humano (es preciso recordar que no existe humano de la forma y proporción de la escultura del florentino).

Lo humano se ha petrificado, se ha apartado en todo del modelo en tanto que el bloque se humaniza produciéndose algo nuevo, un ente metafórico que antes no existía, en el cual el tema (ser humano) y la materia (mármol) se transparentan y nos dejan ver a través, cómo una cubre al otro y al mismo tiempo lo revela en una mágica transubstanciación.

Ahora ¿qué ocurre cuando el tema se impone a la materia? Pues, ésta se desvirtúa, pierde vitalidad y no nos convence ya que sólo nos revela una mimesis (el cuerpo humano en este caso).

Otro tanto va cuando la materia ahoga el tema, ya que así nos encontramos ante un despliegue ornamental, en que el mármol lucirá como joya sin transparentar imagen alguna.

La obra está realizada cuando queda en esa estrecha tierra de nadie que va entre el tema y la materia-forma. Valga otro ejemplo: si al realizar un estudio de retrato me quedo en una mimesis del modelo, estoy negando a la terracota sus posibilidades expresivas; si actúo sólo 
como un artífice alfarero, lucirá la materia-forma como una joya, pero no podrá reflejar mi intención, no será vehículo de mi voluntad de forma.

Sólo cuando se transparentan los dos elementos antes citados, entonces y sólo entonces, la obra está lograda y esto ocurre cuando no vemos modelo ni materia, sino una mágica tercera entidad.

Esa es la verdadera lucha creativa. Y hemos de agregar cuán fácil es caer en aquello de apartarnos del margen que dejan las dos realidades materiales: Tema y Materia-Forma, entre las cuales corre un sendero fantasmagórico, donde puede habitar la obra de arte, sólo cuando los factores aparecen abrazados, tanto que no se los puede distinguir ni separar. Es el caso cuando bronce y modelo hacen el milagro de no ser ni lo uno ni lo otro, para engendrar un "como si” que no es otra cosa que una metáfora.

En lo referente a mi hacer, quisiera exponer brevemente sobre mi visión de escultor un orden de relatar experiencias en lo que a aspectos relativos a este proceso concierne.

Quisiera partir de lo que dijera Leonardo: ¿Qué es la pintura sino poesía que se ve? Si, como ya se dijo, consideramos al arte metáfora, el tema o la preocupación por él, carece a mi ver de toda importancia. Lo que sí la tiene es el trato que a él se dé. Por tanto cualquier cosa puede ser pretexto para mi creación, lo que desde ya es posible de observar en variados artistas. Basta pensar que a Gutiérrez de Cetina lo recordamos por el sencillo y maravilloso madrigal a unos ojos. Así, el rostro de una mujer, la charla diaria, un paisaje, de súbito ejerce en mí un extraño embrujo, que me obliga a transcribir estas particulares experiencias originándose de ese modo el proceso de la creación.

Esto, naturalmente, exige un orden formal y así a la vivencia madura sigue un proceso de reflexión con lápiz en la mano. ¿No es esto el dibujar? Al principio, la imagen se corporiza vaga y sutil primero para devenir en clara y pensante; es el momento de enfrentar la tridimensionalidad a través de bocetos. 
Es mi costumbre hacerlo teniendo presente la materia definitiva que he de emplear, pudiendo así afirmar desde el primer momento del proceso que la imagen tiene relación directa con la materia escultórica. Es verdad, imagen, materia y técnica marchan de la mano, pudiendo sufrir la otra alteraciones en el proceso de búsqueda por muchas causas, entre las cuales no poca importancia tiene la información técnica o plástica que al respecto recibo mientras está ella en gestación.

Al respecto debo agregar que la relación del formato es una de las alternativas que va directamente relacionada con materia y técnica.

Quisiera destacar la importancia del azar, desde que inicio el mundo coloquio con la materia; la intuición me permite escuchar su voz guiándome sensualmente. Es aquí donde debo hacer un esfuerzo para olvidar dibujos, estudios previos.

En este trance sólo cuenta piedra, madera o barro para sacar de ellos el mayor partido. Es la materia rica, sensual, sugerente, la tenacidad del granito, el cristal del mármol, brillo pastoso del bronce: son quienes guían el cincel y logran el contacto entre ella y el escultor, acto del más duro amor en que se lleva a cabo la creación.

Parece que arte es un camino algo sinuoso y en cada recodo vemos extenderse dimensiones en las que el sueño encuentra alimento para devenir forma, de este modo, accidentes en el proceso de creación, dan acceso a dichas dimensiones y desde allí comenzaremos a recorrerlas.

He intentado mostrar algunas de mis vivencias y reflexiones, las que desde luego, por ser absolutamente personales, no pretendo que correspondan necesariamente a otros creadores. Más bien constituyen una confesión de mi hacer de escultor. 


\section{ALGUNAS OBRAS DEL ESCULTOR MATIAS VIAL}
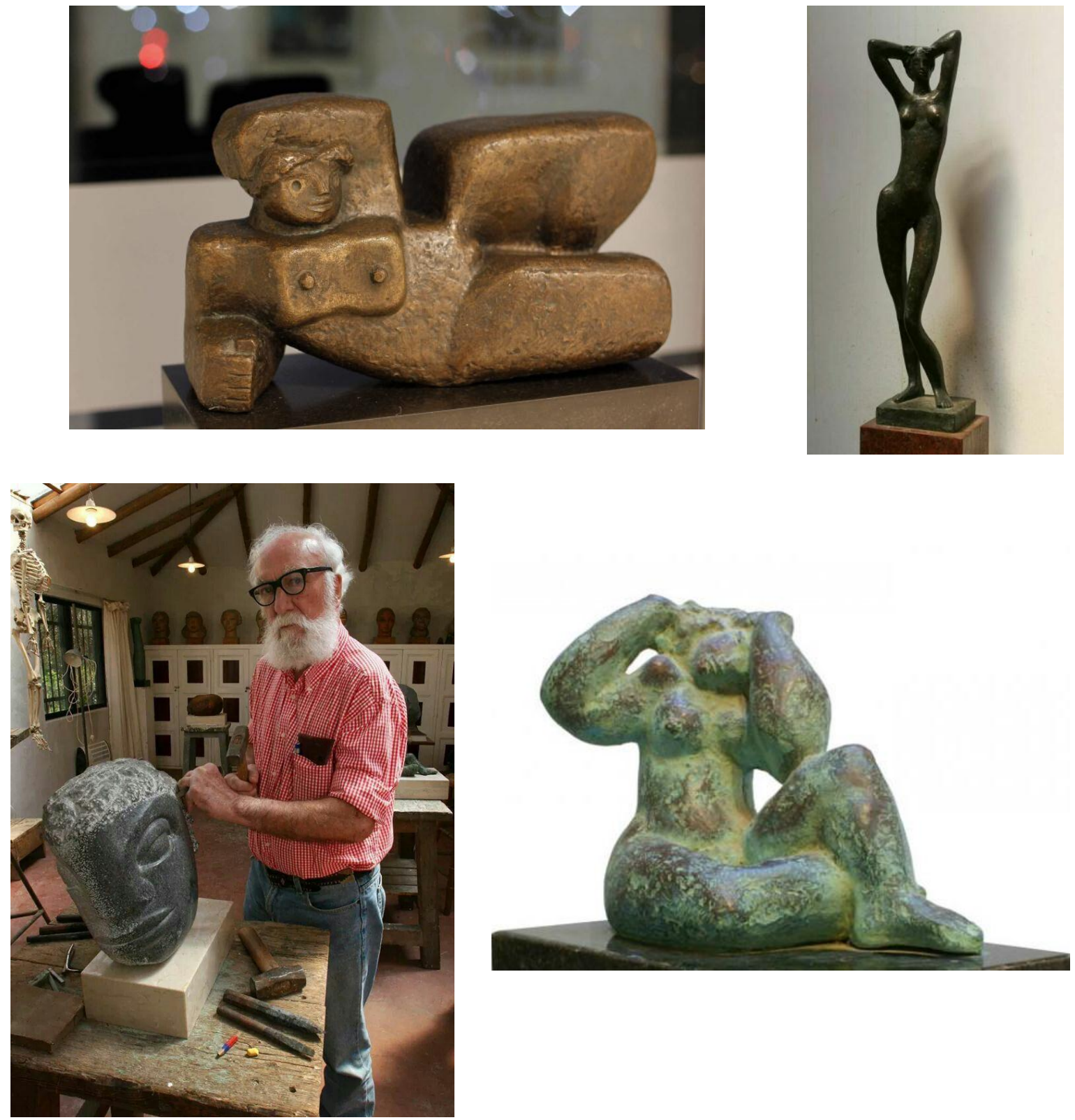

Cuadernos Judaicos ISSN: 0718-8749

Volumen Aniversario 50 años 